\title{
SI00A9 regulates cisplatin chemosensitivity of squamous cervical cancer cells and related mechanism
}

This article was published in the following Dove Press journal:

Cancer Management and Research

\section{Chuchu Zhao* \\ Ermei Lu* \\ Xiaoli Hu \\ Huihui Cheng \\ Jian-An Zhang \\ Xueqiong Zhu}

Department of Obstetrics and Gynecology, The Second Affiliated Hospital of Wenzhou Medical University, Wenzhou, Zhejiang 325027 , China

*These authors contributed equally to this work
Correspondence: Xueqiong Zhu Department of Obstetrics and Gynecology, The Second Affiliated Hospital of Wenzhou Medical University, No. 109 Xueyuan Xi Road, Wenzhou, Zhejiang 325027, China

Tel +8657788002796

Fax +8657788832693

Email zjwzzxq@163.com
Objective: Our previous research has shown that the expression of S100 calcium-binding protein A9 (S100A9) in tumor cells was associated with neoadjuvant chemotherapy sensitivity in cervical squamous cell carcinoma. In the present study, we altered the expression of S100A9 through infecting lentivirus, investigated its effect on the chemosensitivity to cisplatin of cervical cancer cells and then made a primary exploration of the involved mechanism.

Materials and methods: Lentivirus was employed to upregulate and downregulate S100A9 expression in SiHa cells. The protein expression level of apoptotic-related proteins Bcl-2 and Bax, drug resistance-related proteins multiple drug resistance protein 1 (MRP1), P glycoprotein (P-gp), glutathione-S-transferase- $\pi$ (GST- $\pi$ ), lung resistance-related protein (LRP), and FOXO1 signaling pathway related proteins was detected by Western blot. The CCK- 8 assay was used to examine chemosensitivity to cisplatin, and the proportion of apoptosis cells was analyzed by the flow cytometry.

Results: S100A9 overexpression could obviously increase the IC50 value of SiHa cells to cisplatin and decrease the apoptosis rate induced by cisplatin. Downregulation of S100A9 led to the opposite results. In S100A9 overexpression SiHa cells, the expression level of Bcl-2, LRP, GST- $\pi$, p-AKT, p-ERK, p-FOXO1, and Nanog was significantly increased, while FOXO1 expression was decreased. The opposite results were observed in S100A9 knockdown SiHa cells. Conclusion: Downregulation of S100A9 could significantly increase apoptosis rate, resulting in enhancing sensitivity of SiHa cells to cisplatin, which may be related to Bcl-2, GST- $\pi$, and LRP protein and by altering the AKT/ERK-FOXO1-Nanog signaling pathway.

Keywords: S100A9, cervical cancer, Bcl-2, GST- $\pi$, LRP, FOXO1, cisplatin, chemosensitivity

\section{Introduction}

In spite of the widespread use of screening tests and the advancement in treatment methods, cervical cancer is still the fourth most frequently diagnosed cancer in women worldwide, leading to an estimated 527,600 new cases and 265,700 deaths in $2012 .{ }^{1}$ In America, there were 61,380 estimated new cases of cervical cancer and 10,920 estimated deaths in $2017 .^{2}$ Most early-stage cervical cancer can be cured by surgery and/or radiation with or without chemotherapy. ${ }^{3}$ For individuals with locally advanced cervical cancer, primary treatment options contain cisplatin-based combination chemotherapies and concurrent radiation. ${ }^{4}$ However, systemic chemotherapies, especially cisplatin-based regimens, often have severe side effects, such as nephrotoxicity, myelosuppression and digestive tract reactions. ${ }^{5}$ Moreover, patients often develop resistance to chemotherapy, resulting in compromising the efficacy of cisplatin. ${ }^{6}$ The molecular mechanisms underlying cisplatin resistance are complex and are not well understood 
yet. ${ }^{6}$ Therefore, it is essential to screen novel strategies to overcome cisplatin resistance in cervical cancer.

The S100 family contains more than 20 members, which exhibit a high degree of sequence and structural similarity. The term S100 is derived from the solubility of these proteins in $100 \%$ saturated ammonium sulphate. ${ }^{7}$ S100A9 belongs to the S100 family of calcium-binding proteins, and is also called MRP-14 (myeloid related protein of molecular weight $14 \mathrm{kD}){ }^{8}$ S100A9 may exist as a homodimer, heterodimer or heterotetramer. ${ }^{9}$ S100A9 protein has been shown to regulate cell proliferation, differentiation, apoptosis, survival, and migration/ invasion through interacting with some enzymes, receptors, transcription factors. ${ }^{10}$ Arachidonic acid, receptor for advanced glycation end products, Toll-like receptor 4, the major fatty acid transporter CD36, matrix metalloproteinases, fibronectin, and heparin sulfate glycosaminoglycans are ligands of calcium bound S100A9. ${ }^{11}$ Increased levels of S100A9 were found in many tumors, including ovarian, gastric, esophageal, colon, pancreatic, bladder, thyroid and breast carcinomas. ${ }^{12}$

In our previous study, we detected the expression of S100A proteins in the paired tumor samples (pre- and postchemotherapy) obtained from 68 squamous cervical cancer patients who were treated with cisplatin-based neoadjuvant chemotherapy and radical hysterectomy, and revealed that S100A9 protein expression in tumor cells correlated with tumor response to chemotherapy. ${ }^{13}$ Similar to our research, Zhu et $\mathrm{al}^{14}$ found that cervical squamous carcinoma patients, who received the concurrent chemoradiotherapy, with negative staining of S100A9 showed significantly lower 5-year overall survival rate than those with positive staining. The above results suggested that S100A9 may be associated with the chemosensitivity of squamous cervical cancer. However, we also found the expression intensity of S100A9 was statistically higher in post-chemotherapy cervical cancer tissues in comparison with that in pre-chemotherapy. ${ }^{13}$ In our further study, ${ }^{15}$ four squamous cervical cancer cell lines were selected with diverse human papillomavirus expression, SiHa, C-33A, CaSki, and MS751, and found that the S100A9 mRNA and protein were moderately expressed in SiHa cells. In addition, S100A9 could promote squamous cervical cancer cell proliferation, migration and invasion. Therefore, whether S100A9 promotes or inhibits cisplatin sensitivity remains controversial.

In the present study, we used lentivirus to upregulate or downregulate the expression of S100A9 in SiHa cells, followed by exploring the role of S100A9 expression on the cisplatin sensitivity in squamous cervical cancer and elucidating the related molecular mechanisms, in order to overcome the chemoresistance in cervical cancer and provide a thread to explore new treatment strategies.

\section{Materials and methods Cell lines and culture}

The human cervical cancer cell line SiHa was obtained from Shanghai Cell Biology Medical Research Institute, Chinese Academy of Sciences, and maintained as a monolayer in Dulbecco's modified Eagle's medium (DMEM) (Gibco, Thermo Fisher Scientific, Waltham, MA, USA) supplemented with $10 \%$ fetal bovine serum (Gibco, Thermo Fisher Scientific) and $100 \mu \mathrm{g} / \mathrm{mL}$ streptomycin. The cells were incubated at $37^{\circ} \mathrm{C}$ in a humidified atmosphere of $5 \% \mathrm{CO}_{2}$.

\section{Lentivirus production and transduction of target cells}

The S100A9 sequences were amplified by polymerase chain reaction, confirmed by sequencing, and then inserted into the lentiviral expression vector pLVX-IRES-ZsGreen 1 (donated by the School of Medical Lab Science, Wenzhou Medical University). The four pGFP-C-shLenti vectors inserted with four different S100A9 small hairpin RNAs (shRNAs) and the negative control plasmid were purchased from Origene (Rockville, MD, USA). To produce virus particles, together with two packaging plasmids psPAX2 and G protein of the vesicular stomatitis virus (VSV-G) envelope plasmid pMD2.G (donated by Dr Luzhe Sun, The University of Texas Health Science Center at San Antonio), S100A9-pLVX-IRES-ZsGreen1, S100A9-pGFP-C-shLenti and the control vector $(5.0 \mu \mathrm{g})$ were transfected into $293 \mathrm{~T}$ cells at the ratio of 5:2:3 for 48 hours, using lipofectamine 3,000 (Thermo Fisher Scientific). SiHa cells were seeded in 60-mm dish and cultured in DMEM medium without antibiotics for 24 hours. Then, SiHa cells were transduced with recombinant lentiviral particles with the help of polybrene (final concentration $8 \mu \mathrm{g} / \mathrm{mL}$ ). To produce polyclonal cells with stable expression of S100A9, the infected GFP-positive cells were sorted by flow cytometry (FACSAria II, BD Biosciences, San Jose, CA, USA); the S100A9 downregulation cells were selected by $2 \mu \mathrm{g} / \mathrm{mL}$ puromycin (SigmaAldrich Co., St Louis, MO, USA). The primers and sh-RNA used for gene overexpression or downexpression are listed in Table 1 . All cells were confirmed by Western blot.

\section{Western blot analysis}

The cells were washed with PBS and lysed with RIPA buffer (150 mM NaCl, 1.0\% Nonidet P-40, 0.5\% sodium deoxycholate, $0.1 \%$ sodium dodecyl sulfate, $50 \mathrm{mM}$ Tris, $\mathrm{pH} 8.0$ ) containing protease inhibitor cocktail (Beyotime, Shanghai, 
Table I Description of the selected genes and specific primers used in this study

\begin{tabular}{lll}
\hline Gene & Primer name & Primer sequence (5'-3') \\
\hline SI00A9 & SI00A9-F & CCG CTC GAG ATG ACT TGC AAA ATG TCG CAG \\
S100A9shA & SI00A9-R & ATA TAT GGA TCC TTA GGG GGT GCC CTC CCG AG \\
S100A9shB & SI00A9shRNA-A & TGT CGC AGC TGG AAC GCA ACA TAG AGA CC \\
SI00A9shC & SI00A9shRNA-B & CAT CAA CAC CTT CCA CCA ATA CTC TGT GA \\
S100A9shD & SI00A9shRNA-C & CAT CAA CAC CTT CCA CCA ATA CTC TGT GA \\
\hline
\end{tabular}

China). The lysates were incubated on ice for 30 minutes. After centrifugation at $12,000 \mathrm{~g}$ at $4^{\circ} \mathrm{C}$ for 20 minutes, the supernatant was collected and bicinchoninic acid assay (Beyotime) was used for protein qualification. Equal amounts of protein were loaded onto a $12 \%$ sodium dodecyl sulfate-polyacrylamide gel and then transferred onto a $0.45 \mu \mathrm{m}$ or $0.22 \mu \mathrm{m}$ polyvinylidene difluoride membrane (Millipore, Boston, MA, USA). The membranes were blocked with $5 \%$ non-fat milk in Tris-buffered saline containing $0.1 \%$ Tween-20 at room temperature for 2 hours, and incubated at $4^{\circ} \mathrm{C}$ overnight with each primary antibodies: Bax, Bcl-2, AKT, p-AKT, ERK, p-ERK, FOXO1, p-FOXO1, Nanog (1:1,000, Cell Signaling Technology, Beverly, MA, USA), MRP1, P-gp, LRP, GST- $\pi(1: 1,000$, Abcam, San Francisco, CA, USA), and $\alpha$-tubulin antibody (1:2,000, Beyotime). Then the membranes were incubated with the secondary antibody for 2 hours at room temperature. Enhanced chemiluminescence reagent (Beyotime) was used to detect the protein signals. All values were normalized to those of $\alpha$-tubulin. All experiments were performed in triplicate.

\section{Cell sensitivity to cisplatin}

The viability of the SiHa cells after treatment with cisplatin (Sigma-Aldrich Co.) was determined using the CCK-8 assay (Cell Counting Kit-8; Dojindo Laboratories, Tokyo, Japan). The cells were digested and cultured in 96-well plates for 24 hours. Subsequently, the cells were treated with various concentrations of cisplatin $(0,1,2.5,5,10,20,30,40,50$, and $60 \mu \mathrm{M}$ ) for 24 or 48 hours. Then the drug solution was replaced with fresh medium, and $10 \mu \mathrm{L} /$ well CCK-8 solution was added to the medium. The cells were incubated at $37^{\circ} \mathrm{C}$ for 2 hours, and absorbance measured at $450 \mathrm{~nm}$ absorption spectra in a microplate reader (Bio-Rad Laboratories Inc., Hercules, CA, USA). Cell viability was calculated as follows: $\%$ cell viability $=\left(\mathrm{OD}_{450}\right.$ of test well $-\mathrm{OD}_{450}$ of blank well $) /$ $\left(\mathrm{OD}_{450}\right.$ of control well $-\mathrm{OD}_{450}$ of blank well $) \times 100 \%$. The experiments were repeated three times. The half-maximal inhibitory concentration (IC50) was defined as the concentration of cisplatin that inhibited cell viability by $50 \%$ which was calculated by GraphPad Prism software.

\section{Apoptosis assay}

Apoptosis was assessed using the annexin V-phycoerythrin (PE) and 7-amino-actinomycin D (7-AAD) apoptosis detection kit (BD, Franklin Lakes, NJ, USA) according to the manufacturer's instructions. After treatment with $10 \mu \mathrm{M}$ cisplatin for 24 hours, $\mathrm{SiHa}$ cells were collected, washed with phosphate buffer saline twice and digested by $0.25 \%$ trypsin and dissociated into single cell. Then the cells were double-stained with $5 \mu \mathrm{L}$ annexin V-PE and 7-AAD. Stained cells were analyzed by flow cytometry (BD). The experiment was repeated three times.

\section{Plate clone formation assay}

Four different kinds of cells were seeded into each well of 6-well plates at the density of 400/well and cultured in DMEM containing $10 \%$ fetal bovine serum for 14 days. After washing with PBS, each well was fixed with methyl alcohol for 15 minutes and stained with crystal violet for 10 minutes.

\section{Statistical analysis}

Statistical analysis was performed with Statistical Product and Service Solutions (SPSS) 19.0 statistical software (IBM Corporation, Armonk, NY, USA). All data values in the text were continuous variables and normal distribution, expressed as mean $\pm \mathrm{SD}$. The differences were analyzed using one-way ANOVA with least significance difference method. Statistically significant differences between two groups were determined by two-tailed unpaired Student's $t$-test. Differences were considered statistically significant at a 2-sided $P$-value of less than 0.05 .

\section{Results}

\section{Lentivirus-mediated upregulation and downregulation of SI00A9 in $\mathrm{SiHa}$ cells}

To elucidate the functional importance of S100A9, SiHa cells were transfected with S100A9-pLVX-IRES-ZsGreen1 lentivirus or S100A9-pGFP-B-shLenti to stably enhance or knockdown the expression of S100A9. The efficiency 
of upregulation and downregulation of S100A9 is shown in Figures 1 and 2. The levels of S100A9 expression in the empty-vector group showed no significant difference compared to the control group $(P>0.05)$

As shown by Western blot analysis (Figure 2), transfection of SiHa cells with S100A9-pLVX-IRES-ZsGreen1 lentivirus dramatically enhanced the expression of S100A9 by $\sim 10-$ fold. SiHa cells transfected with S100A9-pGFP-B-shLenti showed the maximum suppression of S100A9 expression by approximately 3 -fold.

\section{Effect of SI00A9 on the sensitivity of $\mathrm{SiHa}$ cells to cisplatin}

The cell proliferation treated with cisplatin was further evaluated with CCK-8 assay. The IC50 values were calculated from the cell viability plots. Results revealed that upregulation of
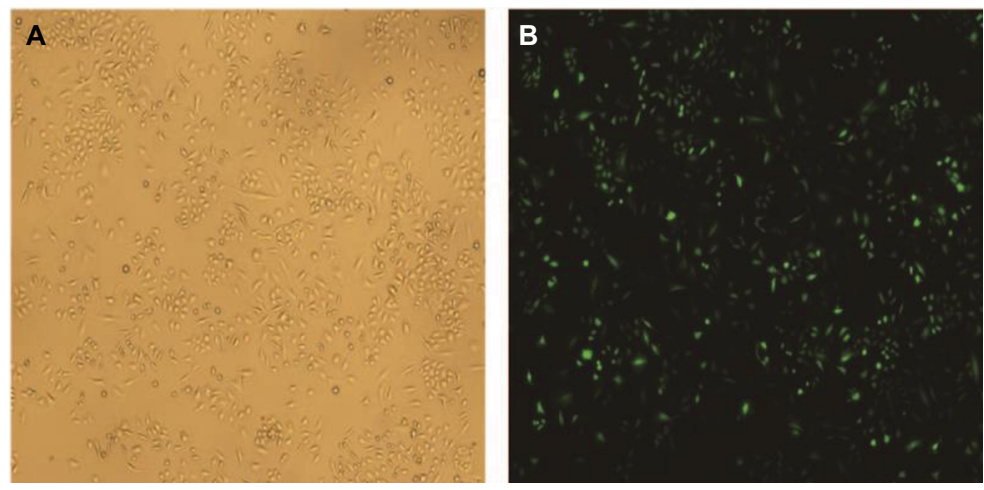

Figure I The transfection efficiency of lentivirus after transfecting SiHa cells for 48 hours.

Notes: $(\mathbf{A})$ Image of SiHa cells at normal light $(\times 100)$. (B) GFP expression in SiHa cells following transfection with SI00A9-pLVX-IRES-ZsGreen I lentivirus at fluorescent $(\times 100)$. The transduction efficiency of lentivirus was $93 \%$.

A

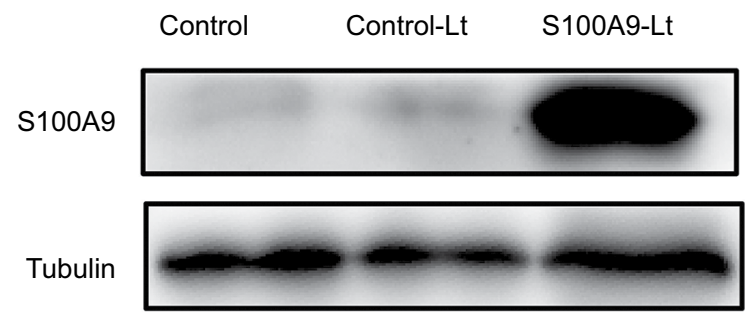

$14 \mathrm{kDa}$

$55 \mathrm{kDa}$

C

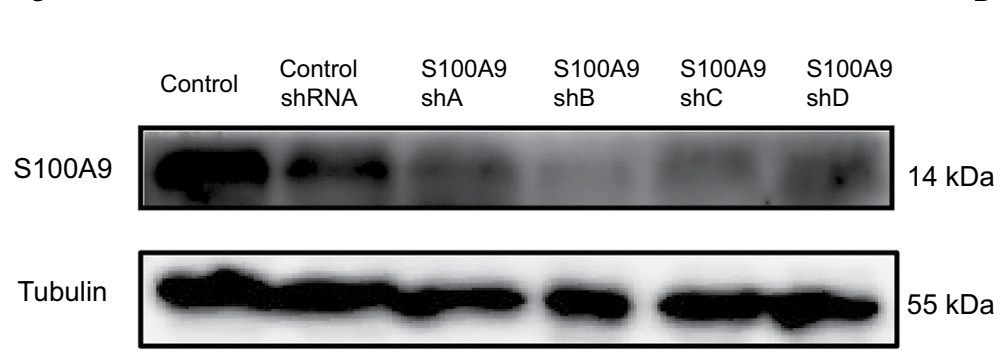

D
B
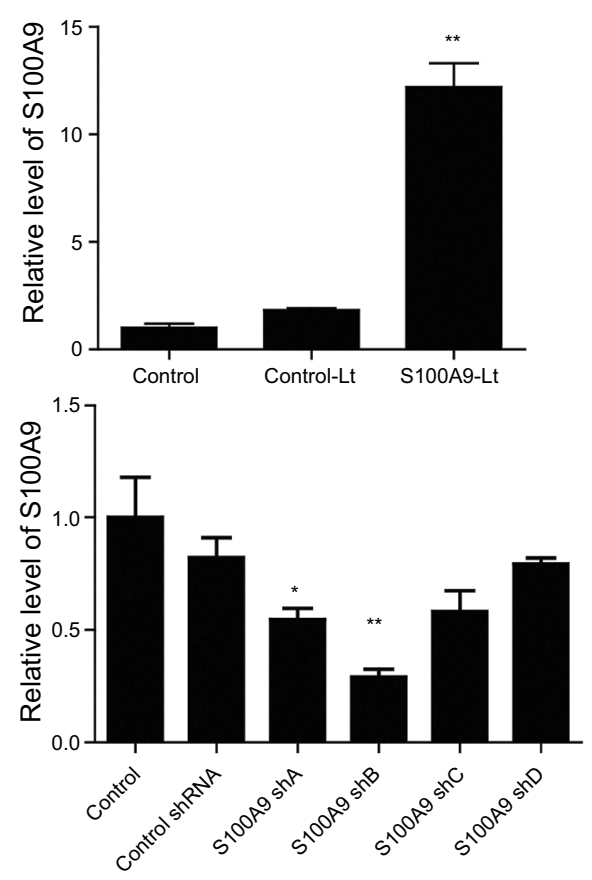

Figure 2 SI00A9 upregulation and downregulation by SI00A9-pLVX-IRES-ZsGreen one lentivirus and SI00A9-pGFP-C-shLenti lentivirus.

Notes: (A and B) SI00A9 protein expression in SiHa cells transfected with SI00A9-pLVX-IRES-ZsGreen one lentivirus was detected by Western blot. (C and D) SI00A9 protein expression in $\mathrm{SiHa}$ cells transfected with four various SI00A9 shRNA. Data are mean \pm SD from triplicate experiments. $* P<0.05$ compared with the control and negative control group (control-Lt or control shRNA group). ${ }^{* *}<<0.01$ compared with the control and negative control group.

Abbreviations: control-Lt, control lentivirus; SI00A9-Lt, SI00A9 lentivirus. 
S100A9 decreased the sensitivity of SiHa cells to cisplatin compared with the control-Lt group, whether $\mathrm{SiHa}$ cells were treated for 24 hours or 48 hours (Figure $3 \mathrm{~A}$ and C) and the IC50 value was dramatically increased (Table 2). As illuminated by Figure $3 \mathrm{~B}$ and D, compared to the negative control group, downregulation of S100A9 led to decrease survival rate of SiHa cells with a significantly decreased IC50 value to cisplatin (Table 3 ).

\section{Influences of SI00A9 expression on cell apoptosis caused by cisplatin}

The underlying mechanisms of S100A9 effect on chemosensitivity were further studied. SiHa cells were treated with cis- platin at $10 \mu \mathrm{M}$ concentration for 24 hours and flow cytometry was used to detect the apoptotic cells. S100A9 overexpression SiHa cells had significantly lower apoptotic rate and S100A9 knockdown SiHa cells had obviously higher apoptotic rate, compared with their negative control group respectively (Figure 4), indicating that S100A9 could significantly inhibit the cell apoptosis of $\mathrm{SiHa}$ cells caused by cisplatin.

\section{SI00A9 affected apoptosis related protein $\mathrm{Bcl}-2$ expression in $\mathrm{SiH}$ a cells}

As S100A9 protein could affect the apoptosis rate of $\mathrm{SiHa}$ cells induced by cisplatin, the expression level of apoptosis
A

24 hours overexpression

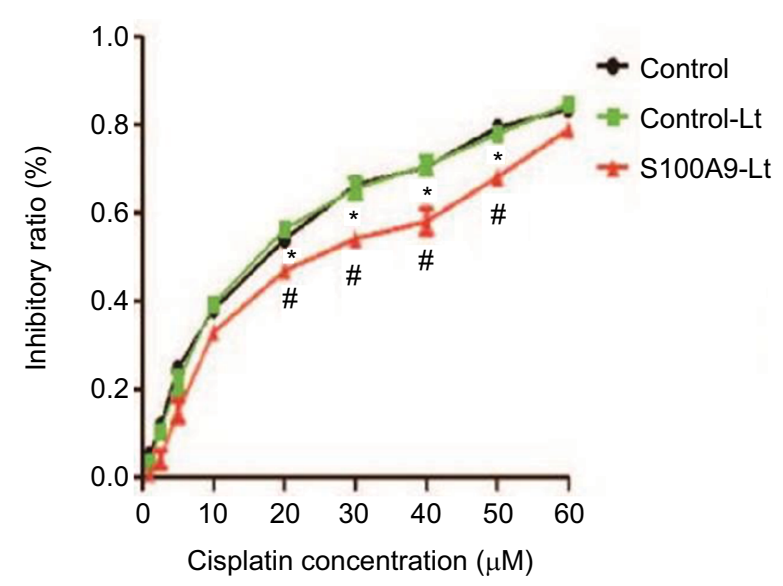

C

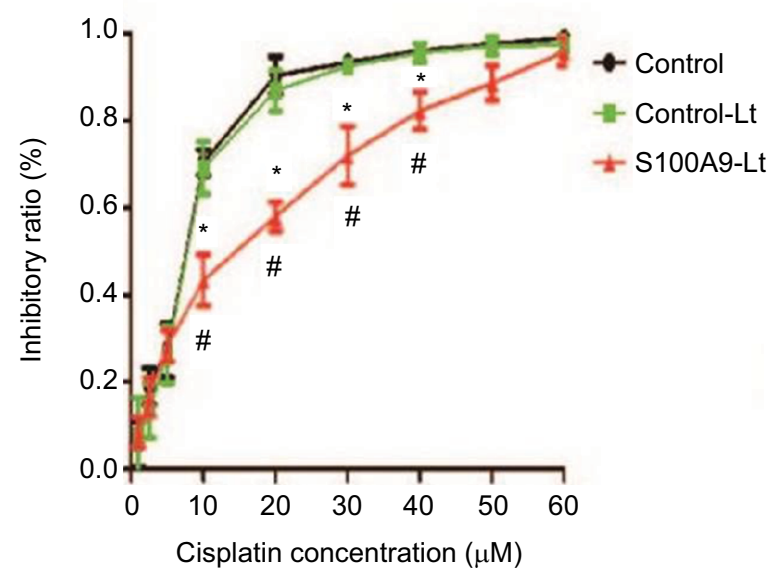

B 24 hours knockdown

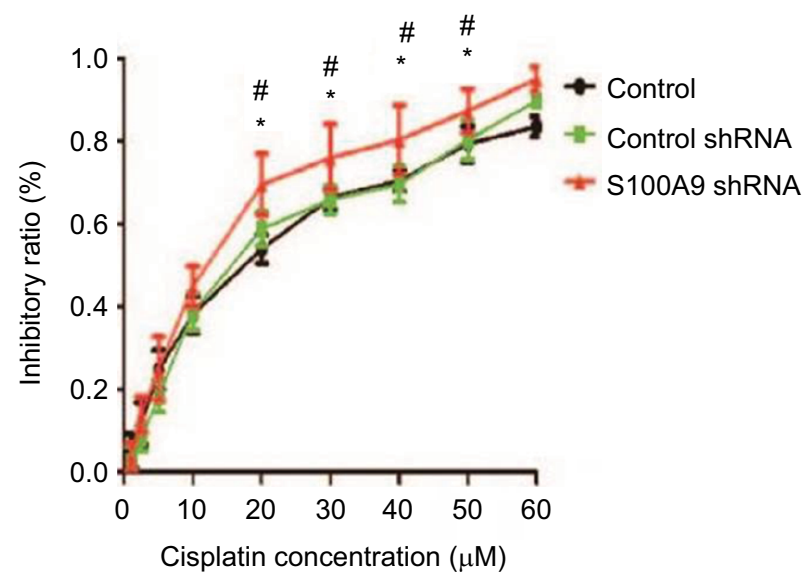

D

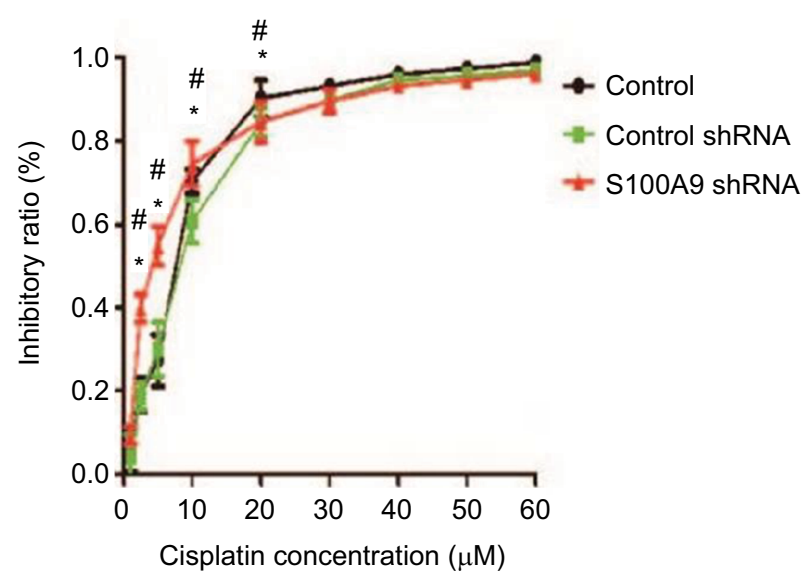

Figure 3 Effect of SI00A9 on the sensitivity of $\mathrm{SiHa}$ cells to cisplatin.

Notes: (A and B) SI00A9 overexpression and knockdown SiHa cells treated with cisplatin for 24 hours. (C and D) SI00A9 overexpression and knockdown SiHa cells treated with cisplatin for 48 hours. Data are mean \pm SD from triplicate experiments. *Compared with control group, $P<0.05$. ${ }^{*}$ Compared with negative control group (control-Lt or control shRNA group) $P<0.05$.

Abbreviations: control-Lt, control lentivirus; SI00A9-Lt, SI00A9 lentivirus. 
Table 2 IC50 values of cisplatin for SI00A9-overexpressed $\mathrm{SiHa}$ cells

\begin{tabular}{lll}
\hline Cell line & \multicolumn{2}{l}{ Cisplatin IC $_{50}$} \\
\cline { 2 - 3 } & $\mathbf{2 4}$ hours & $\mathbf{4 8}$ hours \\
\hline Control & 17.24 & 6.54 \\
Control-Lt & 16.78 & 6.97 \\
SI00A9-Lt & 26.30 & 12.21 \\
\hline
\end{tabular}

Abbreviations: control-Lt, control lentivirus; SI00A9-Lt, SI00A9 lentivirus.

Table 3 IC50 values of cisplatin for SI00A9 knockdown $\mathrm{SiHa}$ cells

\begin{tabular}{lll}
\hline Cell line & \multicolumn{2}{l}{ Cisplatin IC $_{50}$} \\
\cline { 2 - 3 } & $\mathbf{2 4}$ hours & $\mathbf{4 8}$ hours \\
\hline Control & 17.89 & 6.85 \\
Control-shRNA & 17.21 & 7.49 \\
SI00A9-shRNA & 11.22 & 3.91 \\
\hline
\end{tabular}

related-proteins Bcl-2 and Bax in SiHa cells after the change of S100A9 protein was detected by Western blot. As shown in Figure 5, the Bcl-2 protein level was significantly enhanced after S100A9 upregulated by lentivirus in SiHa cells, and decreased after S100A9 downregulated. Therefore, S100A9 could influence Bcl-2 protein expression. However, the expression level of Bax protein was not affected by S100A9 expression.

\section{SI00A9 upregulated drug resistance- associated proteins expression in $\mathrm{SiHa}$ cells}

Multiple drug resistance protein 1 (MRP1), P glycoprotein (P-gp), lung-related resistance protein (LRP) and glutathioneS-transferase- $\pi$ (GST- $\pi$ ) are well-known drug resistancerelated proteins in cancer cells. The expression levels of
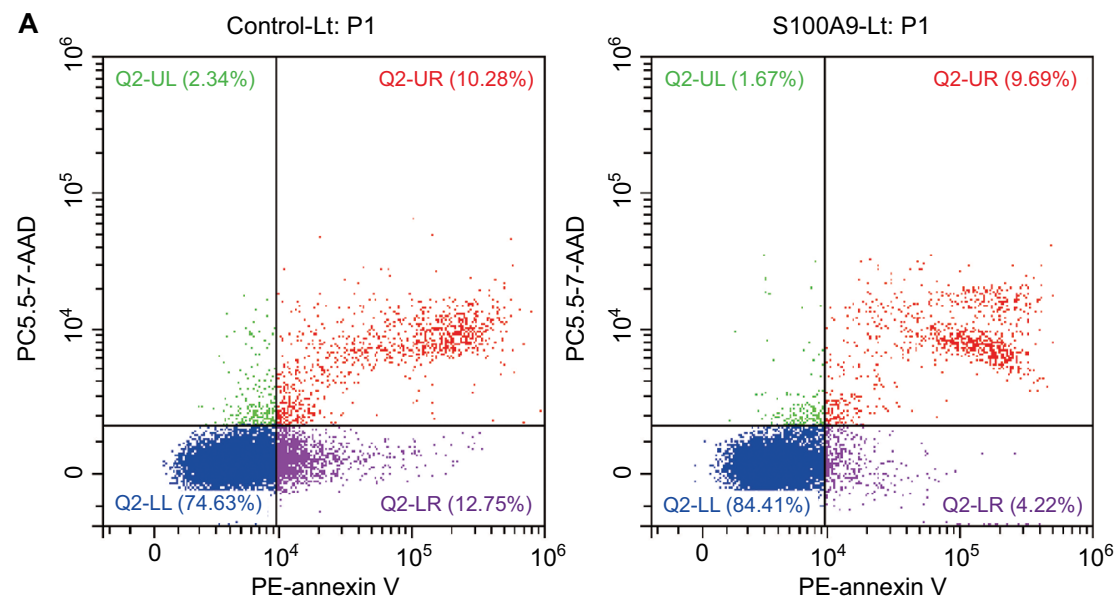

B
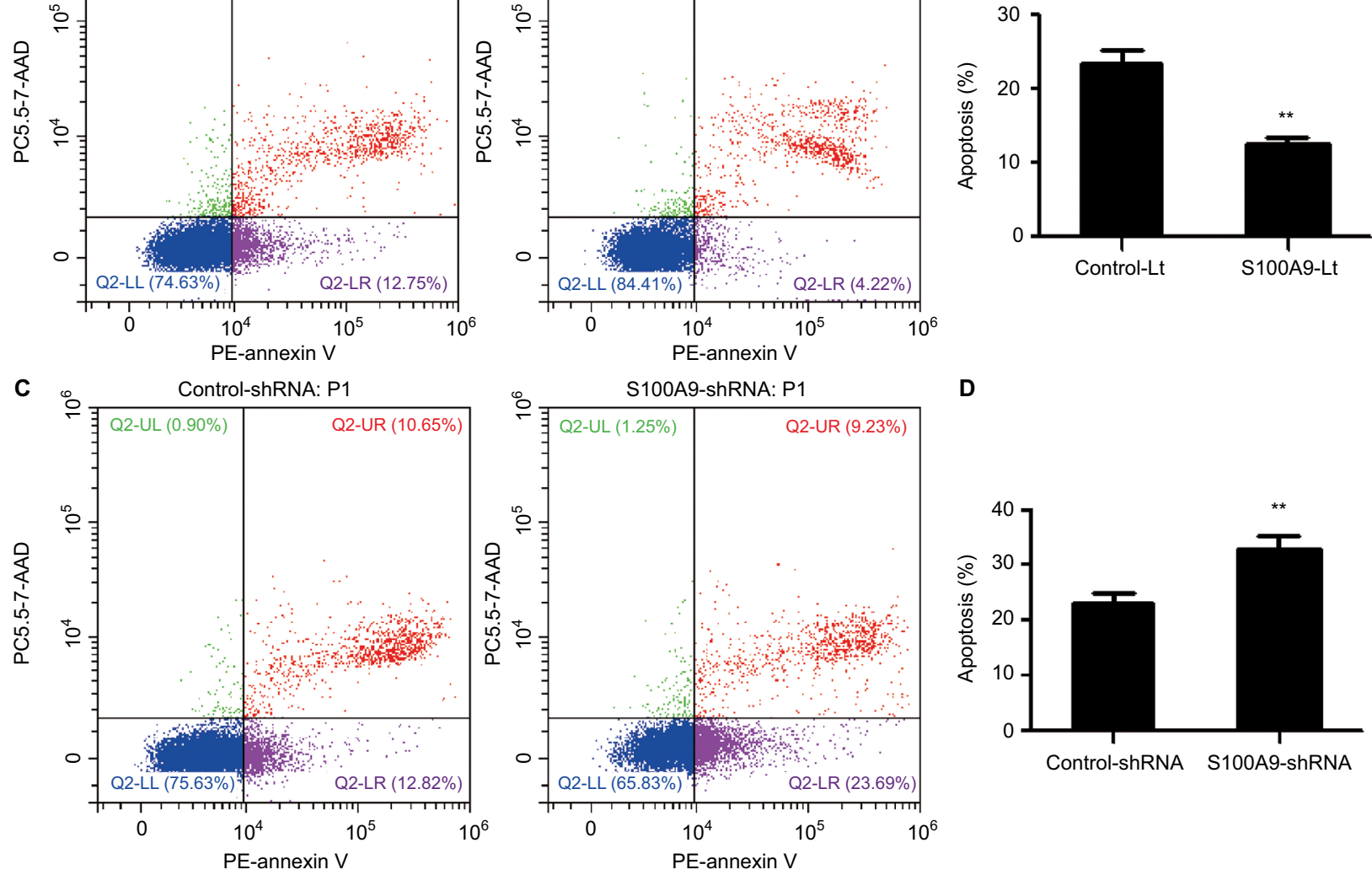

Figure 4 The effect of SI00A9 on the apoptosis of $\mathrm{SiH}$ a cells induced by cisplatin.

Notes: (A and B) The apoptosis percentage of blank vector group and SI00A9 overexpression group. (C and D) The apoptosis percentage of control group and SI00A9 knockdown group. Apoptosis percentage was analyzed by annexin V-PE/7-AAD staining. Data are mean \pm SD from triplicate experiments. $* * P<0.01$.

Abbreviations: control-Lt, control lentivirus; SI00A9-Lt, SI00A9 lentivirus; PE, phycoerythrin. 


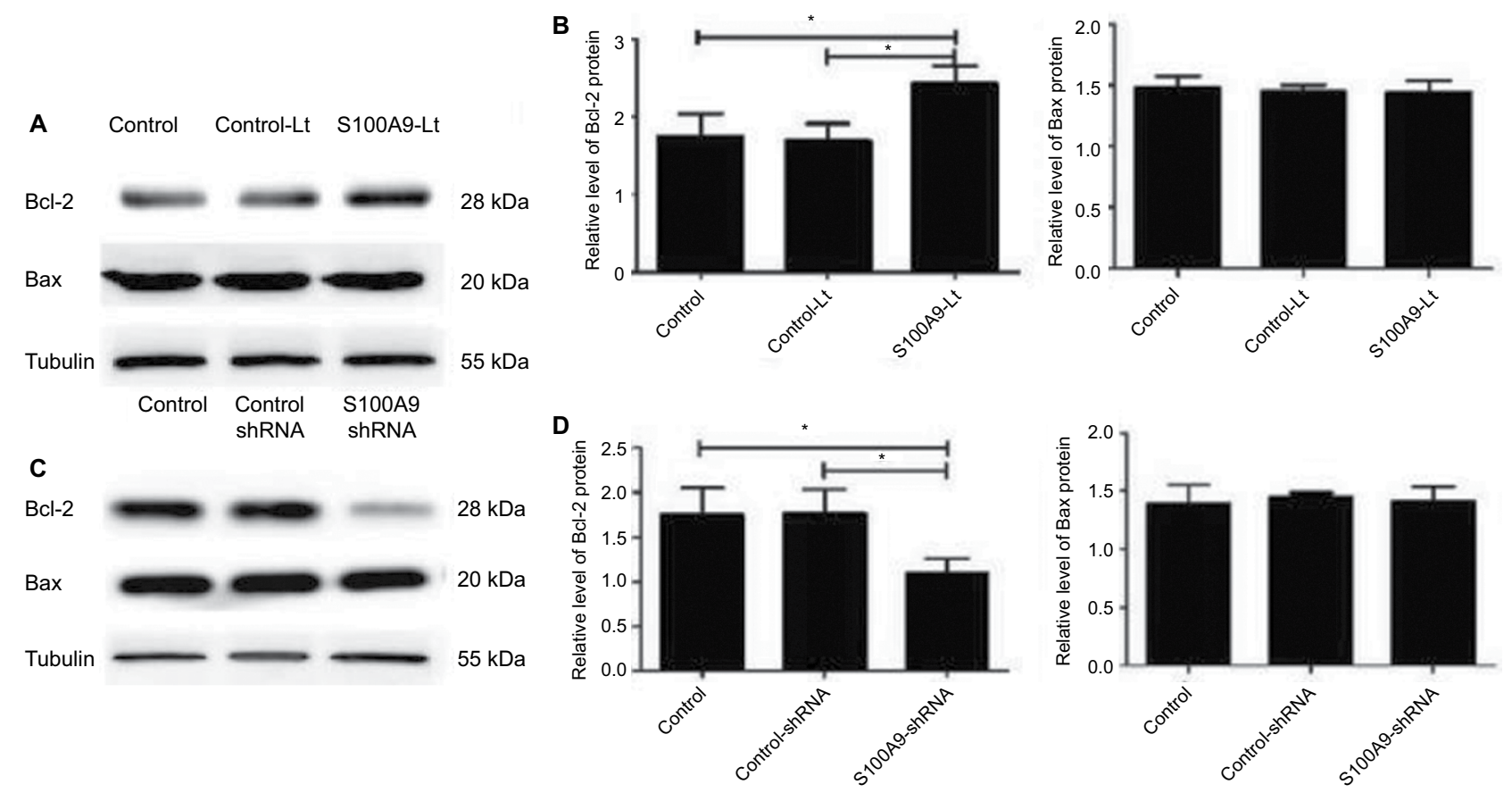

Figure 5 Levels of apoptosis-related proteins Bcl-2 and Bax in SI00A9 overexpression and knockdown SiHa cells.

Notes: (A and $\mathbf{C})$ Bcl-2 and Bax proteins expression was analyzed by Western blot. (B and $\mathbf{D})$ The data are presented as relative expression level of Bcl-2 and Bax proteins normalized to tubulin. Data are mean \pm SD from triplicate experiments. $* P<0.05$.

Abbreviation: Bcl-2, B-cell lymphoma-2; control-Lt, control lentivirus; SI00A9-Lt, SI00A9 lentivirus.

MRP1, P-gp, GST- $\pi$ and LRP in SiHa cells were detected by Western blot. As showed in Figure 6, P-gp protein level tended to increase compared to the control groups when S100A9 expression was upregulated. While S100A9 expression was downregulated, P-gp protein had a tendency to decrease. However, there was no significant difference. The expression of MRP1 protein was not affected by S100A9 expression.

Western blot was performed to evaluate the expression of LRP and GST- $\pi$ protein, another two MDR-related proteins, in S100A9 upregulated and downregulated SiHa cells. Results revealed a remarkable increased LRP and GST- $\pi$ protein expression in S100A9 overexpression $\mathrm{SiHa}$ cells. Meanwhile, LRP and GST- $\pi$ protein expression significantly decreased in S100A9 knockdown SiHa cells (Figure 6).

\section{SI00A9 levels correlate with $\mathrm{p}-\mathrm{AKT}$, p-ERK, p-FOXOI, and Nanog protein expression in $\mathrm{SiHa}$ cells}

To further identify the potential mechanism for regulation of tumor cell cisplatin chemosensitivity by S100A9, Western blot analysis was performed. We detected a striking increase of p-AKT, p-ERK, p-FOXO1, and Nanog in S100A9-overexpressed $\mathrm{SiHa}$ cells, and the opposite results were observed in the S100A9 knockdown SiHa cells (Figure 7). Moreover, FOXO1 was downregulated in S100A9-overexpressed group and upregulated in S100A9 knockdown group (Figure 7). Furthermore, S100A9 overexpression remarkably increased the number of clones formed, whereas the knockdown of S100A9 inhibited their ability to form colonies, as assessed by the colony formation assay (Figure 8 ). These data suggest that upregulation of S100A9 could augment the tumorigenicity of $\mathrm{SiHa}$ cells and promote $\mathrm{SiHa}$ cells acquiring stemness.

\section{Discussion}

S100A9 is reported to be overexpressed in a variety of cancers ${ }^{16}$ and is implicated in chemotherapy resistance. ${ }^{17-22}$ The results of studies concerning the effect of S100A9 protein on chemotherapy are contradictory. Needle-biopsied tissues of breast cancer patients prior to neoadjuvant chemotherapy (doxorubicin and docetaxel) were collected, and mass spectrometry and immunohistochemistry found that S100A9 was robustly upregulated in the sensitive group. ${ }^{17}$ In an in vitro study, knocking down S100A9 could enhance human cervical squamous carcinoma cell SiHa and C-33A invasion ability and tumor cell viability against paclitaxel treatment. ${ }^{18}$ Conversely, other studies concluded that S100A9 could enhance the chemotherapy resistance of cancers. In NK/T cell lymphoma patients treated with pegaspargase/ gemcitabine, higher levels of S100A9 protein were found in non-responders compared with responders through serum 


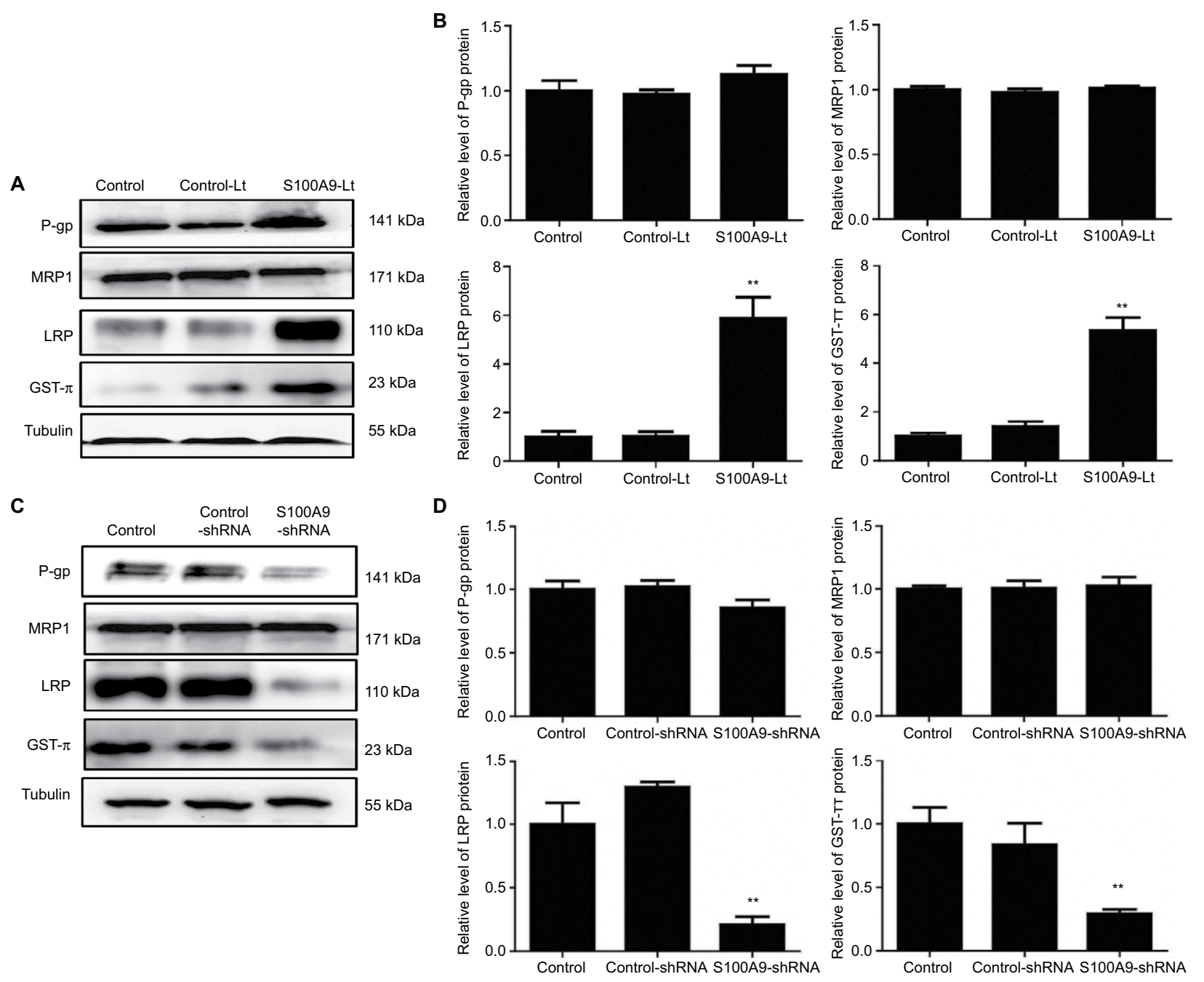

Figure 6 Levels of drug resistance-related proteins MRPI, P-gP, LRP and GST- $\pi$ in SI00A9 overexpression and knockdown SiHa cells.

Notes: (A and C) MRPI, P-gP, LRP, and GST- $\pi$ proteins expression was analyzed by Western blot. (B and D) The data are presented as relative expression level of MRPI, P-gP, LRP, and GST- $\pi$ proteins normalized to tubulin. Data are mean \pm SD from triplicate experiments. $* P<0.05$ compared with the control and negative control group. $* * P<0.0$ l compared with the control and negative control group.

Abbreviations: MRPI, multiple drug resistance protein I; P-gp, P glycoprotein; LRP, lung-related resistance protein; GST- $\pi$, glutathione-S-transferase- $\pi$; control-Lt, control lentivirus; SI00A9-Lt, SI00A9 lentivirus.

proteomic analysis. ${ }^{19}$ Benzyl butyl phthalate could increase the secretion of S100A9 in tumor myeloid-derived suppressor cells, and therefore exacerbate the breast cancer resistance to doxorubicin with cyclophosphamide. ${ }^{20}$ In muscle invasive bladder cancer, S100A9 positivity predicted disease progression after chemotherapy. ${ }^{21}$ In epithelial ovarian cancer, S100A9 was also found upregulated in chemoresistant tumors using Affymetrix HGU133A microarray. ${ }^{22}$ Nevertheless, the relationship between S100A9 and cervical cancer cell sensitivity to cisplatin was still unclear. In the present study, the results revealed that upregulated S100A9 protein significantly increased the IC50 values of cisplatin in $\mathrm{SiHa}$ cells, while inhibition of the S100A9 protein expression obviously lowered the IC50 values of cisplatin. Therefore, we considered that S100A9 might relate to the cisplatin resistance of SiHa cells.
Cisplatin, also named cis-diamminedichloroplatinum (II), is a platinum coordination compound and a major chemotherapeutic drug for the treatment of cervical carcinomas. DNA is the cytotoxic target of cisplatin. Cisplatin damages DNA through forming covalent adducts with purine DNA bases and the drug-DNA adducts induce cell cycle arrest and apoptosis. ${ }^{23}$ However, two problems in cisplatin treatment are that the sensitivity needs to be improved and the cellular toxicity also increases significantly along with the increase of dosage. ${ }^{24}$ The molecular mechanism underlying cisplatin resistance is multifactorial, and mainly associated with the following factors: 1) less accumulation of intracellular platinum compounds; 2) enhanced ability of tumor cells to repair damaged DNA; 3) upregulation of antiapoptotic proteins; and 4) enhanced epithelial-mesenchymal transition. ${ }^{6}$ The precise mechanism of how S100A9 protein regulates cervical cancer 


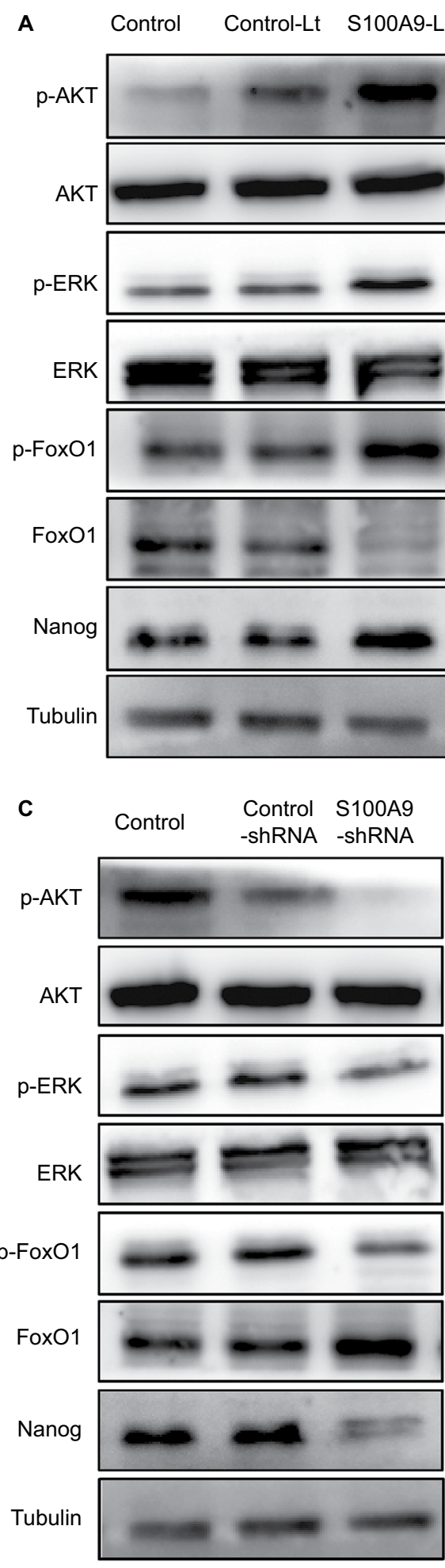

$65 \mathrm{kDa}$

$65 \mathrm{kDa}$

$44 / 42 \mathrm{kDa}$
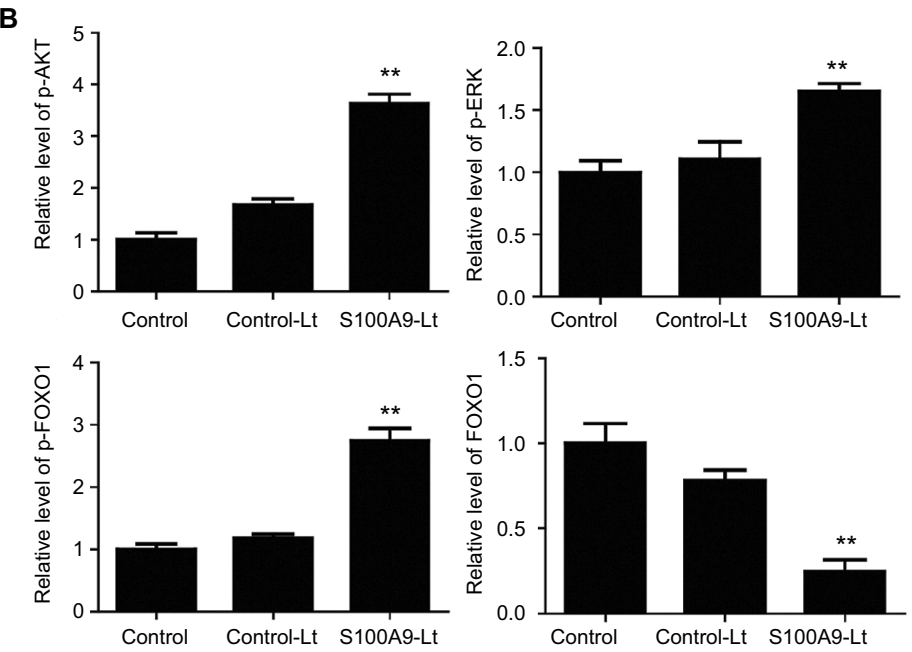

$82 \mathrm{kDa}$
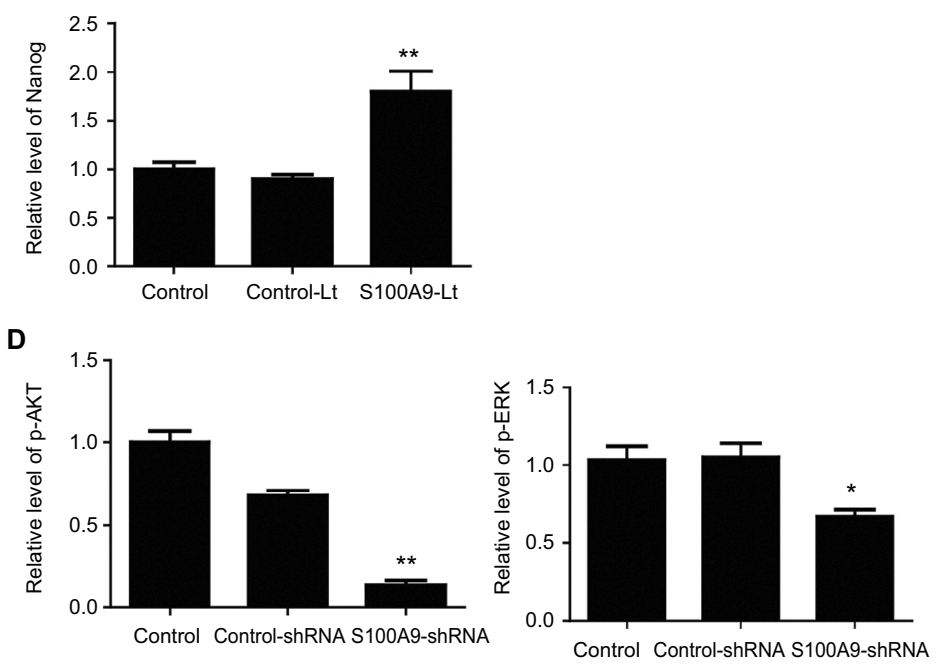

$44 / 42 \mathrm{kDa}$

Control Control-shRNA S100A9-shRNA
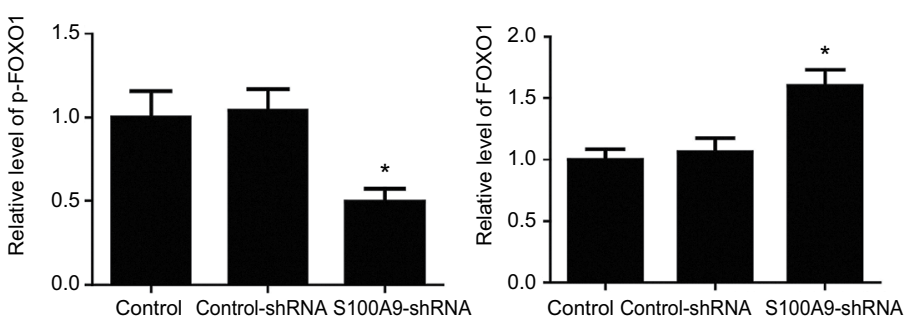

$82 \mathrm{kDa}$

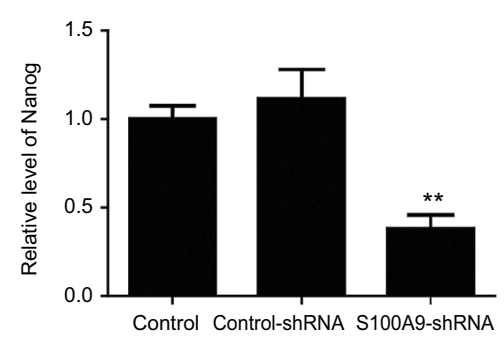

Figure 7 Levels of p-AKT, AKT, p-ERK, ERK, p-FOXOI, FOXOI, and Nanog in SI00A9 overexpression and knockdown SiHa cells.

Notes: (A and C) p-AKT, AKT, p-ERK, ERK, p-FOXOI, FOXOI, and Nanog proteins expression was analyzed by Western blot. (B and D) The data were presented as relative expression level of $\mathrm{p}$-AKT, AKT, p-ERK, ERK, p-FOXOI, FOXOI, and Nanog proteins normalized to tubulin. Data are mean \pm SD from triplicate experiments. $* P<0.05$ compared with the control and negative control group. ${ }^{*} * P<0.01$ compared with the control and negative control group.

Abbreviations: ERK, extracellular regulated protein kinases; $\mathrm{p}$-ERK, phosphorylated extracellular regulated protein kinases; FOXO, forkhead box protein O; $\mathrm{p}-\mathrm{FO}$ ( $\mathrm{XO}$, phosphorylated forkhead box protein O; control-Lt, control lentivirus; SI00A9-Lt, SI00A9 lentivirus. 


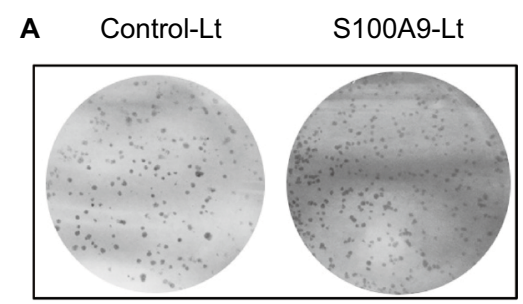

B Control-shRNA

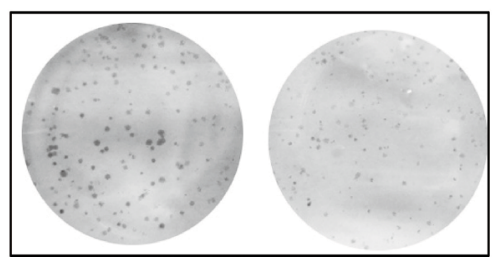

Figure 8 The effects of SI00A9 expression on colony formation. Notes: (A) SI00A9 overexpression, (B) SI00A9 knockdown.

Abbreviations: Control-Lt, control lentivirus; SI00A9-Lt, SI00A9 lentivirus.

cell sensitivity to cisplatin is poorly understood up to now. In the current study, we provided evidence that S100A9 was related to the cervical cancer cells cisplatin resistance, and may be through the inhibition of apoptosis.

Apoptosis pathways involve multiple proteins, and the Bcl-2 family proteins, especially Bcl-2 and Bax, are the critical ones. ${ }^{6}$ In various human cancers, the decrease of Bcl-2 expression conferred cisplatin sensitivity. ${ }^{25-28}$ In cervical cancer, down-regulation of NDRG2 could enhance the sensitivity of Hela cells to cisplatin treatment via inhibiting Bcl-2 expression. ${ }^{25}$ microRNA 873 decreased the level of the $\mathrm{Bcl}-2$ protein and enhanced sensitivity to cisplatin in the glioma cells. ${ }^{26}$ In cervical cancer, suppression of N-Myc downstream regulated gene two could enhance sensitivity of Hela cells to cisplatin through significantly inhibited Bcl-2 expression. ${ }^{27}$ Knocking down phosphoglycerate dehydrogenase significantly increased cisplatin chemotherapy sensitivity of HeLa cells and was connected with the reduction of Bcl-2 protein. ${ }^{28}$ In this study, the results indicated that overexpression of S100A9 raised the level of Bcl-2 protein, while downexpression of S100A9 inhibited the level of Bcl-2 protein, but Bax protein expression was not varied. Therefore, S100A9 influenced the sensitivity of SiHa cells to cisplatin maybe by means of regulating apoptosis via $\mathrm{Bcl}-2$ protein but not Bax protein.

The ATP-binding cassette transporter proteins, including MRP1 and P-gp, are known to play a role in the phenomenon of multidrug resistance in cancer. ${ }^{29}$ MRP1 and P-gp are transport proteins and commonly protect cells by effluxing chemotherapeutic agents. ${ }^{30}$ The overexpression of MRP1 and P-gp in cancer cells results in reduction of intracellular platinum compound concentration. ${ }^{31}$ Whether the effect of S100A9 on SiHa cells cisplatin sensitivity involved MRP1 and P-gp has not been reported yet. In the present study, results showed that the expression of MRP1 and P-gp protein was not altered by S100A9 expression. So, MRP1 and P-gp might not be involved in the S100A9 regulation of cisplatin sensitivity in SiHa cells.

LRP is another protein related to chemoresistance which does not belong to the ATP-binding cassette transporter family. LRP is encoded by the MVP gene which is on the short arm of chromosome 16 (16p11.2). ${ }^{32}$ Clinical trials showed that the expression of LRP was significantly correlated with the MDR of various tumors, and the expression level of LRP was positively correlated with multidrug resistance. ${ }^{33}$ Several groups have demonstrated that ectopic expression of LRP in hematopoietic tumors such as multiple myeloma or acute leukemia may result in poor therapeutic effect. ${ }^{34,35}$ Our results found that LRP protein expression was downregulated in S100A9 knockdown SiHa cells, while LRP protein expression was upregulated in S100A9-overexpressed SiHa cells. This may represent one of the mechanisms to explain the decreased sensitivity of S100A9-overexpressed $\mathrm{SiHa}$ cells to cisplatin.

GST- $\pi$, a member of the GST family, is also a non-transporter-based MDR, which functions by altering the activity of enzyme systems, resulting in drug sequestration in intracellular vesicles. ${ }^{36}$ As a pivotal multifunctional enzyme, GST- $\pi$ plays an important role in cellular detoxification. A growing body of evidence showed that GST- $\pi$ was overexpressed in many tumors compared to the surrounding normal tissues and in various drug-resistant cancer cell line. ${ }^{37}$ More importantly, GST- $\pi$ has been demonstrated as a drug resistance protein in gynecological cancers. ${ }^{38}$ Recent studies have demonstrated that GST- $\pi$ plays a key role in regulating the MAP kinase pathway which participates in fundamental cellular processes such as growth, proliferation, differentiation, migration and apoptosis. ${ }^{39}$ Given our findings that S100A9 could regulate GST- $\pi$ expression in SiHa cells, we suspect that S100A9 is likely implicated in the regulation of drug resistance in cervical cancer.

FOXO1 is a member of the Forkhead box (Fox) family. The evolutionarily conserved transcription factor is a subclass of the forkhead family, which consists of four members. ${ }^{40}$ FOXO1 regulates diverse gene expression and controls a wide spectrum of cellular processes. Deregulation of FOXO1 has a crucial role in the development and progression of many types of cancer. ${ }^{41}$ FOXO1 exerts its antitumor effect by promoting apoptosis, inducing differentiation, and inhibiting tumorigenicity and self-renewal. ${ }^{42}$ FOXO1 is mainly regulated by a variety of post-translational modifications, including 
phosphorylation, acetylation and ubiquitylation. ${ }^{43}$ Under stress conditions, FOXO1 enters the nucleus to promote the expression of pro-apoptotic genes. ${ }^{42}$ Aberrant overactivation of PI3K/AKT and MEK/ERK signaling can phosphorylate and inhibit FOXO1. ${ }^{44} \mathrm{After}$ being phosphorylated by related proteins, FOXO1 is blocked in the cytoplasm and is degraded, inhibiting its transcriptional activity. ${ }^{44} \mathrm{FOXO} 1$ also plays an important role in maintaining cellular pluripotency, and can directly regulate the expression of Nanog, OCT4, and SOX2 in human embryonic stem cells..$^{45,46} \mathrm{But}$, the role of FOXO1 in cervical cancer cells is unclear.

In an in vitro study reported by Zhu et al, ${ }^{18}$ the effects of S100A9 on the biological behavior of SiHa and C-33A human cervical squamous carcinoma cell were found to be related to the phosphatidylinositol 3-kinase/Akt signaling pathway. In the present study, the results showed that overexpression of S100A9 in SiHa cells could promote p-AKT, p-ERK, p-FOXO1 and Nanog expression. Our results suggest that ectopic S100A9 expression induced a significant upregulation of $\mathrm{p}$-AKT and $\mathrm{p}$-ERK protein expression in SiHa cells. Subsequently, p-AKT and p-ERK interacts with FOXO1 and promotes its phosphorylation. AKT and ERK induced FOXO1 phosphorylation promotes its nuclear exclusion, and subsequent degradation of FOXO1. Reduced FOXO1 expression loses the inhibitory effect on tumor stem cells and further promotes $\mathrm{SiHa}$ cells acquiring stem cell-like properties, which is also confirmed by a plate clone formation assay in the present study. Therefore, the expression of pluripotent markers, such as Nanog, increased. This makes SiHa cells resistant to cisplatin chemotherapy.

Taken together, we hypothesize that S100A9 reduces the sensitivity of cervical cancer SiHa cells to cisplatin by the following effects. First, S100A9 may change the expression of multidrug-resistant portion GST- $\pi$, LRP and apoptosis related protein Bcl-2 and affect the apoptosis process. Secondly, S100A9 can promote the phosphorylation of FOXO1 through AKT and ERK signaling pathway, which further inhibits FOXO1-mediated transcription of pro-apoptotic gene and promotes tumor cell survival. Finally, the phosphorylation of FOXO1 induced by S100A9 overexpression can promote the expression of pluripotent markers and promote $\mathrm{SiHa}$ cells to maintain a stem cell-like phenotype, consequently resistant to cisplatin chemotherapy. Downregulation of S100A9 could significantly increase apoptosis rate, resulting in enhanced sensitivity of SiHa cells to cisplatin, which may be related to Bcl-2, GST- $\pi$ and LRP protein and the altered AKT/ERKFOXO1-Nanog signaling pathway. The detailed mechanisms and precise signaling pathway need further study.

\section{Acknowledgments}

This work was sponsored by grants from the National Natural Science Foundation of China (no. 81372381) and Science and Technology project of Wenzhou City (no. H20150003). The study sponsors had no involvement in the collection, analysis and interpretation of data, or in the writing of the manuscript.

\section{Disclosure}

The authors report no conflicts of interest in this work.

\section{References}

1. Torre LA, Bray F, Siegel RL, Ferlay J, Lortet-Tieulent J, Jemal A. Global cancer statistics, 2012. CA Cancer J Clin. 2015;65(2):87-108.

2. Siegel RL, Miller KD, Jemal A. Cancer statistics, 2017. CA Cancer J Clin. 2017;67(1):7-30.

3. Salicrú SR, de La Torre JFV, Gil-Moreno A. The surgical management of early-stage cervical cancer. Curr Opin Obstet Gynecol. 2013;25(4):312-319.

4. Al-Mansour Z, Verschraegen C. Locally advanced cervical cancer: what is the standard of care? Curr Opin Oncol. 2010;22(5):503-512.

5. Nematbakhsh M, Pezeshki Z, Eshraghi Jazi F, et al. Cisplatin-induced nephrotoxicity; protective supplements and gender differences. Asian Pac J Cancer Prev. 2017;18(2):295-314.

6. Zhu H, Luo H, Zhang W, Shen Z, Hu X, Zhu X. Molecular mechanisms of cisplatin resistance in cervical cancer. Drug Des Devel Ther. 2016;10:1885-1895.

7. Donato R, Cannon BR, Sorci G, et al. Functions of S100 proteins. Curr Mol Med. 2013;13(1):24-57.

8. Odink K, Cerletti N, Brüggen J, et al. Two calcium-binding proteins in infiltrate macrophages of rheumatoid arthritis. Nature. 1987;330(6143):80-82.

9. Korndörfer IP, Brueckner F, Skerra A. The crystal structure of the human (S100A8/S100A9)2 heterotetramer, calprotectin, illustrates how conformational changes of interacting alpha-helices can determine specific association of two EF-hand proteins. J Mol Biol. 2007;370(5):887-898.

10. Marenholz I, Heizmann CW, Fritz G. S100 proteins in mouse and man: from evolution to function and pathology (including an update of the nomenclature. Biochem Biophys Res Commun. 2004;322(4):1111-1122.

11. Källberg E, Vogl T, Liberg D, et al. S100A9 interaction with TLR4 promotes tumor growth. PLoS One. 2012;7(3):e34207.

12. Leanderson T, Liberg D, Ivars F. S100A9 as a pharmacological target molecule in inflammation and cancer. Endocr Metab Immune Disord Drug Targets. 2015;15(2):97-104.

13. Jin L, Shen Q, Ding S, Jiang W, Jiang L, Zhu X. Immunohistochemical expression of Annexin A2 and S100A proteins in patients with bulky stage IB-IIA cervical cancer treated with neoadjuvant chemotherapy. Gynecol Oncol. 2012;126(1):140-146.

14. Zhu H, Pei HP, Zeng S, et al. Profiling protein markers associated with the sensitivity to concurrent chemoradiotherapy in human cervical carcinoma. J Proteome Res. 2009;8(8):3969-3976.

15. Zhang W, Chen M, Cheng H, Shen Q, Wang Y, Zhu X. The role of calgranulin $B$ gene on the biological behavior of squamous cervical cancer in vitro and in vivo. Cancer Manag Res. 2018;10:323-338.

16. Markowitz J. Carson WE 3rd. Review of S100A9 biology and its role in cancer. Biochim Biophys Acta. 2013;1835(1):100-109.

17. Yang WS, Moon HG, Kim HS, et al. Proteomic approach reveals FKBP4 and S100A9 as potential prediction markers of therapeutic response to neoadjuvant chemotherapy in patients with breast cancer. $J$ Proteome Res. 2012;11(2):1078-1088.

18. Zhu H, Wu TC, Chen WQ, et al. Roles of galectin-7 and S100A9 in cervical squamous carcinoma: clinicopathological and in vitro evidence. Int J Cancer. 2013;132(5):1051-1059. 
19. Zhou Z, Li Z, Sun Z, et al. S100A9 and ORM1 serve as predictors of therapeutic response and prognostic factors in advanced extranodal $\mathrm{NK} / \mathrm{T}$ cell lymphoma patients treated with pegaspargase/gemcitabine. Sci Rep. 2016;6:23695.

20. Hsu YL, Hung JY, Tsai EM, et al. Benzyl butyl phthalate increases the chemoresistance to doxorubicin/cyclophosphamide by increasing breast cancer-associated dendritic cell-derived CXCL1/GRO $\alpha$ and S100A8/ A9. Oncol Rep. 2015;34(6):2889-2900.

21. Kim WT, Kim J, Yan C, et al. S100A9 and EGFR gene signatures predict disease progression in muscle invasive bladder cancer patients after chemotherapy. Ann Oncol. 2014;25(5):974-979.

22. Ju W, Yoo BC, Kim IJ, Kim JW, Kim SC, Lee HP. Identification of genes with differential expression in chemoresistant epithelial ovarian cancer using high-density oligonucleotide microarrays. Oncol Res. 2009;18(2-3):47-56.

23. Ciarimboli G. Membrane transporters as mediators of cisplatin effects and side effects. Scientifica. 2012;2012:473829-18.

24. Kilic U, Sahin K, Tuzcu M, et al. Enhancement of cisplatin sensitivity in human cervical cancer: epigallocatechin-3-gallate. Front Nutr. 2014; $1: 28$

25. Tung MC, Lin PL, Cheng YW, et al. Reduction of microRNA-184 by E6 oncoprotein confers cisplatin resistance in lung cancer via increasing Bcl-2. Oncotarget. 2016;7(22):32362-32374.

26. Chen X, Zhang Y, Shi Y, et al. miR-873 acts as a novel sensitizer of glioma cells to cisplatin by targeting Bcl-2. Int J Oncol. 2015;47(4):1603-1611.

27. Liu J, Yang L, Zhang J, et al. Knock-down of NDRG2 sensitizes cervical cancer Hela cells to cisplatin through suppressing Bcl-2 expression. BMC Cancer. 2012;12:370.

28. Jing Z, Heng W, Xia L, et al. Downregulation of phosphoglycerate dehydrogenase inhibits proliferation and enhances cisplatin sensitivity in cervical adenocarcinoma cells by regulating Bcl-2 and caspase-3. Cancer Biol Ther. 2015;16(4):541-548.

29. Winter SS, Ricci J, Luo L, et al. ATP Binding Cassette C1 (ABCC1/ MRP1)-mediated drug efflux contributes to disease progression in T-lineage acute lymphoblastic leukemia. Health. 2013;5(5A):41-50.

30. Lu JF, Pokharel D, Bebawy M. MRP1 and its role in anticancer drug resistance. Drug Metab Rev. 2015;47(4):406-419.

31. Abdallah HM, Al-Abd AM, El-Dine RS, El-Halawany AM. P-glycoprotein inhibitors of natural origin as potential tumor chemo-sensitizers: a review. J Adv Res. 2015;6(1):45-62.
32. Bouhamyia L, Chantot-Bastaraud S, Zaidi S, et al. Immunolocalization and cell expression of lung resistance-related protein (LRP) in normal and tumoral human respiratory cells. $J$ Histochem Cytochem. 2007;55(8):773-782.

33. Dalton WS, Scheper RJ. Lung resistance-related protein: determining its role in multidrug resistance. J Natl Cancer Inst. 1999;91(19):1604-1605.

34. Krishnakumar S, Mallikarjuna K, Desai N, et al. Multidrug resistant proteins: P-glycoprotein and lung resistance protein expression in retinoblastoma. Br J Ophthalmol. 2004;88(12):1521-1526.

35. Scheffer GL, Wijngaard PL, Flens MJ, et al. The drug resistancerelated protein LRP is the human major vault protein. Nat Med. 1995;1(6):578-582.

36. Zhang Y, Zhou T, Duan J, Xiao Z, Li G, Xu F. Inhibition of P-glycoprotein and glutathione $\mathrm{S}$-transferase-pi mediated resistance by fluoxetine in MCF-7/ADM cells. Biomed Pharmacother. 2013;67(8):757-762.

37. Mao ZP, Zhao LJ, Zhou SH, Liu MQ, Tan WF, Yao HT. Expression and significance of glucose transporter-1, P-glycoprotein, multidrug resistance-associated protein and glutathione S-transferase- $\pi$ in laryngeal carcinoma. Oncol Lett. 2015;9(2):806-810.

38. Soh Y, Goto S, Kitajima M, et al. Nuclear localisation of glutathione $\mathrm{S}$-transferase pi is an evaluation factor for drug resistance in gynaecological cancers. Clin Oncol. 2005;17(4):264-270.

39. Townsend DM, Tew KD. The role of glutathione-S-transferase in anticancer drug resistance. Oncogene. 2003;22(47):7369-7375.

40. Eijkelenboom A, Burgering BM. FOXOs: signalling integrators for homeostasis maintenance. Nat Rev Mol Cell Biol. 2013;14(2):83-97.

41. Coomans de Brachène A, Demoulin JB. FOXO transcription factors in cancer development and therapy. Cell Mol Life Sci. 2016;73(6): 1159-1172.

42. Monsalve M, Olmos Y. The complex biology of FOXO. Curr Drug Targets. 2011;12(9):1322-1350.

43. Yadav RK, Chauhan AS, Zhuang L, Gan B. FoxO transcription factors in cancer metabolism. Semin Cancer Biol. 2018;50:65-76.

44. Xing YQ, Li A, Yang Y, Li XX, Zhang LN, Guo HC. The regulation of FOXO1 and its role in disease progression. Life Sci. 2018;193:124-131.

45. Zhang X, Yalcin S, Lee DF, et al. FOXO1 is an essential regulator of pluripotency in human embryonic stem cells. Nat Cell Biol. 2011;13(9): 1092-1099.

46. Arden KC. FoxOs in tumor suppression and stem cell maintenance. Cell. 2007;128(2):235-237.
Cancer Management and Research

\section{Publish your work in this journal}

Cancer Management and Research is an international, peer-reviewed open access journal focusing on cancer research and the optimal use of preventative and integrated treatment interventions to achieve improved outcomes, enhanced survival and quality of life for the cancer patient. The manuscript management system is completely online and includes

\section{Dovepress}

a very quick and fair peer-review system, which is all easy to use. Visit http://www.dovepress.com/testimonials.php to read real quotes from published authors. 